\title{
Micropropagação de abacaxizeiro cv. Emepa $1^{1}$
}

\author{
Ailton M. de Moraes ${ }^{2}$, Francisco de A. C. Almeida ${ }^{3}$, Riselane de L. A. Bruno ${ }^{4}$, \\ Jorge Cazé Filho ${ }^{5}$, Shirley T. N unes ${ }^{6} \&$ Josivanda P. Gomes ${ }^{3}$
}

\begin{abstract}
RESU MO
Realizou-se esse trabalho com o objetivo de desenvolver um protocolo de micropropagação para o abacaxizeiro cv. Emepa 1, contemplando as fases de estabelecimento de explantes (EE), multiplicação (UM) e enraizamento (EN). Como explantes se utilizaram gemas axilares, desinfestadas e inoculadas em meio MS sólido, contendo diferentes concentrações e combinações de 6-benzilaminopurina (BAP) e de ácido naftalenoacético (ANA). Todas as culturas foram mantidas em sala de crescimento com temperatura de $25 \pm 5^{\circ} \mathrm{C}$ e fotoperíodo de $16 \mathrm{~h}$ luz, a uma intensidade luminosa de $30 \mu \mathrm{mol} \mathrm{m} \mathrm{m}^{-2} \mathrm{~s}^{-1}$. O delineamento experimental utilizado foi inteiramente casualizado, com seis tratamentos na fase $\mathrm{EE}$, oito na fase $\mathrm{MU}$ e quatro na fase $\mathrm{EN}$, dez repetições, sendo a unidade experimental constituída de um frasco contendo um broto. Concluiu-se que o estabelecimento de gemas axilares desta variedade de abacaxizeiro, pode ser realizado em meio de cultivo MS sem a adição de reguladores de crescimento; a multiplicação, em meio de cultura MS suplementado com 2,0 mg L-1 de BAP + 0,5 $\mathrm{mg} \mathrm{L}^{-1}$ de ANA, enquanto a adição do ANA promove o enraizamento dos brotos.
\end{abstract}

Palavras-chave: Ananas comosus var. comosus, gemas axilares, reguladores de crescimento

\section{Micropropagation of pineapple, cv. Emepa 1}

\begin{abstract}
This work aimed to develop a micropropagation protocol of pineapple cv. Emepa 1. The cv. Emepa 1 axillary gems used were disinfested and inoculated in half MS solid with $5.8 \mathrm{pH}$. There was incubation in a growth room with temperature of $25 \pm 5{ }^{\circ} \mathrm{C}$ and photoperiod of $16 \mathrm{~h}$ light at a luminous intensity of $30 \mu \mathrm{mol} \mathrm{m} \mathrm{m}^{-2} \mathrm{~s}^{-1}$. The cv. Emepa 1 micropropagation protocol was developed according to the existing literature, comprising the following phases: establishing of explants (EE); multiplication (MU); extent rooting (EN). A completely randomized design (CRD) was used in all the phases as follows: $\mathrm{EE}$ - DIC with 6 treatments comprised of 10 repetitions containing 1 explants per bottle; MU - CRD with 8 treatments, comprised of 10 repetitions containing 1 explants per bottle. It was concluded that the concentration of $2 \%$ of sodium hypochlorite for 10 min causes gems disinfestations and the establishment can be carried out by means of tillage without any growth regulators. The etiolating can be achieved in MS with $1.86 \mathrm{mg} \mathrm{L}^{-1}$ of ANA and regeneration in MS with $1.8 \mathrm{mg} \mathrm{L}^{-1}$ of the ANA + $2.0 \mathrm{mg} \mathrm{L}^{-1}$ of BAP. For the multiplication, the type of tillage indicated is MS supplemented with $2.0 \mathrm{mg} \mathrm{L}^{-1}$ of BAP $+0.5 \mathrm{mg} \mathrm{L}^{-1}$ of ANA; in extent, the type of crop MS without any dilution causes the highest growth of seedlings whereas the addition of ANA prompts an increase in number and a decrease of seedling's root size and the organic compound favors an increase and development of pineapple seedlings produced in vitro during the acclimatizing phase.
\end{abstract}

Key words: Ananas comosus var. comosus, axillary gems, growth regulators

1 Parte da Tese de Doutorado do primeiro autor apresentada à UFPB/CCA

2 Doutor em Agronomia, Pesquisador da EMEPA/PB, CP 275, CEP 58013-290, João Pessoa, PB. Fone: (83) 8871-2425. E-mail: ailtonmmoraes@hotmail.com

3 UAEA/UFCG, Av. Aprígio Veloso, 882, CEP 58429-140, Campina Grande, PB. Fone: (83) 3310-1550. E-mail: almeida@deag.ufcg.edu.br; josi@deag.ufcg.edu.br

${ }^{4}$ DF/UFPB, CP 22, CEP 58397-000, Areia, PB. Fone: 3362-2300, Ramal: 253. E-mail: lane@cca.ufpb.br

5 Pesquisador da EMEPA/PB. Fone: (83) 3218-5476. E-mail: emepa@netwaybbs.com.br

${ }^{6}$ Graduanda. CSTR/UFCG. Fone: (83) 3423-9713. E-mail: shirlley_nunes@hotmail.com 


\section{INTRODUÇÃO}

A área cultivada com abacaxizeiro no Brasil tem aumentado pouco ao longo dos anos, devido principalmente à pequena oferta de mudas de boa qualidade (Praxedes et al., 2001).

Segundo Cunha \& Reinhardt (2004) o sucesso econômico no cultivo de produtos agrícolas depende sobretudo do uso de material de plantio de boa qualidade, por se tratar do insumo mais importante de qualquer cultura. Em abacaxizeiro, a muda produzida em viveiro a partir de pedaços do talo ou do caule de plantas que já foram colhidas, é adequada para a implantação de plantios com melhor sanidade, especialmente em relação à fusariose, e também para multiplicação de novas variedades; entretanto, esta prática, é muito pouco utilizada em virtude da falta de viveiristas especializados nesta atividade. Já o uso de mudas micropropagadas, isto é, produzidas in vitro por meio de técnicas de cultura de tecidos, fica restrito à introdução de plantas matrizes de novas variedades geradas em programas de melhoramento genético. Essas técnicas vêm sendo largamente aplicadas, não só pela possibilidade de se obter plantas mais resistentes a fatores de estresses bióticos (fusariose) e abióticos (salinidade) mas, também, pela rápida propagação clonal in vitro de novas variedades (Macêdo et al., 2003). No caso do abacaxizeiro (Ananas comosus var. comosus), tais técnicas estão sendo utilizadas comercialmente visando à produção de novas cultivares e ao aumento na quantidade de mudas (Albuquerque, 1998).

A produção de mudas por cultura de tecidos permite obter milhares de mudas a partir de uma única gema, em pequeno período de tempo e totalmente livres de problemas fitossanitários (Teixeira et al., 2001; Firoozabady \& Gutterson, 2003; Barboza et al., 2004).

Para Macêdo et al. (2003), após os primeiros trabalhos de Aghion \& Beauchesne (1960) há, na literatura, um número crescente de estudos que investigam aspectos tais como: sistema de micropropagação (cultura estacionária e por imersão temporária); resposta de diferentes cultivares às condições in vitro; tipo de explante; meio de cultura; tipo e concentração de fitorreguladores (Mathews \& Rongan, 1979; Cabral et al., 1983; Liu et al., 1988; Marciani-Bendezú et al., 1990; Roca \& Mroginski, 1991; Ventura, 1994; dal Vesco et al., 1996; Teng, 1997; Guerra et al., 1999; dal Vesco et al., 2000; Feuser et al., 2001; Sá, 2001); no entanto, além do aprofundamento dos aspectos citados pode-se acrescentar, a esta lista, o estudo das condições físicas de incubação, limpeza clonal, resistência à salinização, hidroponia, anatomia e aclimatação (Praxedes et al., 2001; dal Vesco et al., 2001; Omokolo et al., 2001; Silva et al., 2002; Almeida et al., 2002; Moreira et al., 2003; Macêdo et al., 2003; Barroso et al., 2003; Barboza et al., 2004; Mogollón et al., 2004; Moreira et al., 2006; Barboza et al., 2006).

Com os estudos de micropropagação do abacaxizeiro são exigidas melhorias nos protocolos regenerativos empregados devido, sobretudo, às diferentes respostas dos genótipos aos reguladores de crescimento adicionados aos meios de cultura. Objetivou-se, com este trabalho, portanto, desenvolver um protocolo de micropropagação para o abacaxizeiro cv. Emepa 1.

\section{MATERIAL E MÉTODOS}

Utilizaram-se mudas sadias do tipo coroa de abacaxizeiro cv. Emepa 1, provenientes dos campos experimentais da Empresa Estadual de Pesquisa Agropecuária do Estado da Paraíba - EMEPA/PB. Os experimentos foram realizados no Laboratório de Cultura de Tecidos Vegetais da EMEPA/PB, em condições assépticas utilizando-se, como meio de cultura, o MS (Murashige \& Skoog, 1962), adicionado de $30 \mathrm{~g} \mathrm{~L}^{-1}$ de sacarose e solidificado com $7 \mathrm{~g} \mathrm{~L}^{-1}$ de ágar, com $\mathrm{pH}$ ajustado para 5,8. As culturas foram mantidas em sala de crescimento em temperatura de $25 \pm 5^{\circ} \mathrm{C}$ e fotoperíodo de $16 \mathrm{~h}$ de luz, a uma intensidade luminosa de $30 \mu \mathrm{mol} \mathrm{m} \mathrm{m}^{-2} \mathrm{~s}^{-1}$.

\section{Experimento 1 - Estabelecimento de explantes (EE)}

As mudas do tipo coroa foram desinfestadas em três etapas: (1) imersão em solução de formaldeído a $1 \%$, durante 1 min; (2) após a secagem no laboratório em condições ambiente as mudas foram tratadas por imersão em solução contendo $0,3 \%$ de Derosal $500^{\circledR}$, durante $10 \mathrm{~min}$ e (3) depois do desfolhamento, em câmara de fluxo laminar, as gemas axilares foram extraídas e desinfestadas em álcool a 70\%, por $1 \mathrm{~min}$ em hipoclorito de sódio $(\mathrm{NaClO})$ a $2 \%$ por um tempo de $10 \mathrm{~min}$; na sequiência, foram submetidas a tríplice lavagem em água destilada e deionizada estéril.

As gemas axilares isoladas e desinfestadas foram inoculadas em meio MS suplementado com os reguladores de crescimento BAP (6-benzilaminopurina) e ANA (ácido naftalenoacético) em diferentes concentrações e combinações, estabelecendo-se assim seis tratamentos $\left(\mathrm{em} \mathrm{mg} \mathrm{L} \mathrm{m}^{-1}: \mathrm{T}_{1}=0,0\right.$ de $\mathrm{BAP}+0,0$ de ANA; $\mathrm{T}_{2}=0,5$ de $\mathrm{BAP}+0,125$ de ANA; $\mathrm{T}_{3}=0,5$ de $\mathrm{BAP}+0,5$ de ANA; $\mathrm{T}_{4}=1,0$ de $\mathrm{BAP}+0,5$ de ANA; $\mathrm{T}_{5}=2,0$ de BAP e $\mathrm{T}_{6}=2,0$ de $\mathrm{BAP}+1,0$ de ANA).

Os brotos desenvolvidos foram subcultivados aos 30 dias da inoculação e a avaliação realizada aos 60 dias de cultivo, quantificando-se o número e a altura dos brotos estabelecidos.

\section{Experimento 2 - Multiplicação (MU)}

Utilizaram-se, como explantes, brotos desenvolvidos na primeira fase (EE) em meio MS sem a adição de reguladores de crescimento, os quais foram subcultivados em meio MS, suplementado com BAP e ANA em diversas concentrações e combinações, totalizando oito tratamentos (em $\mathrm{mg} \mathrm{L}^{-1}$ : $\mathrm{T}_{1}=0,0$ de BAP $+0,0$ de ANA; $\mathrm{T}_{2}=1,0$ de BAP; $\mathrm{T}_{3}=1,5$ de BAP; $\mathrm{T}_{4}=2,0$ de BAP; $\mathrm{T}_{5}=2,52$ de BAP; $\mathrm{T}_{6}=1,0$ de $\mathrm{BAP}+0,01$ de ANA; $\mathrm{T}_{7}=2,0$ de $\mathrm{BAP}+0,5$ de ANA e $\mathrm{T}_{8}=2,0$ de BAP $+1,0$ de ANA). Os subcultivos foram realizados aos 30 e 60 dias após o cultivo in vitro e as avaliações aos 30, 60 e 90 dias da inoculação, levando-se em consideração a taxa de multiplicação por broto inoculado.

\section{Experimento 3 - Enraizamento (EN)}

Brotos cultivados em meio MS básico medindo aproximadamente $2 \mathrm{~cm}$ de altura foram selecionados aleatoriamente e transferidos, em câmara de fluxo laminar, para frascos contendo o meio MS suplementado com ANA em quatro concentrações $\left(\mathrm{em} \mathrm{mg} \mathrm{L}^{-1}: \mathrm{T}_{1}=0,0 ; \mathrm{T}_{2}=0,2\right.$; 
$\left.\mathrm{T}_{3}=1,0 ; \mathrm{T}_{4}=2,0\right)$. A avaliação foi realizada aos 30 dias de cultivo tendo em vista o número e o comprimento médio das raízes.

Os dados obtidos nos três experimentos foram submetidos a análise estatística utilizando-se o delineamento inteiramente casualizado (DIC) com 10 repetições por tratamento, sendo a unidade experimental constituída por dez frascos contendo um explante por frasco. Realizou-se a comparação entre as médias pelo teste de Tukey $(\mathrm{p} \leq 0,05)$.

\section{RESULTADOS E DISCUSSÃO}

As análises de variância e os respectivos valores do Teste F do desenvolvimento do protocolo de micropropagação da cv. EMEPA 1 de abacaxizeiro, obtiveram valores significativos a $1 \%$ de probabilidade.

\section{Experimento 1 - Estabelecimento de explantes}

Observa-se, na Tabela 1, para a variável número de brotos desenvolvidos superioridade do tratamento sem reguladores de crescimento sobre os demais suplementados com BAP e ANA, nas concentrações estudadas.

Tabela 1. Número médio e altura de brotos desenvolvidos de abacaxizeiro cv. Emepa 1 em meio de cultura MS suplementado com diferentes concentrações e combinações dos reguladores de crescimento BAP e ANA, aos 60 dias de cultivo in vitro

\begin{tabular}{|c|c|c|c|}
\hline \multicolumn{2}{|c|}{ Tratamentos $\left(\mathrm{mg} \mathrm{L}^{-1}\right)$} & \multirow{2}{*}{$\begin{array}{l}\text { Número de brotos } \\
\text { desenvolvidos }\end{array}$} & \multirow{2}{*}{$\begin{array}{l}\text { Altura dos brotos } \\
\text { (cm) }\end{array}$} \\
\hline \multicolumn{2}{|c|}{ BAP + ANA } & & \\
\hline - & - & $10 \mathrm{a}$ & $0,5 \mathrm{a}$ \\
\hline 0,5 & 0,125 & $8 b$ & $0,4 a b$ \\
\hline 0,5 & 0,5 & $6 c$ & $0,4 a b$ \\
\hline 1,0 & 0,5 & $6 c$ & $0,3 b$ \\
\hline 2,0 & - & $8 b$ & $0,3 b$ \\
\hline 2,0 & 1,0 & $8 b$ & $0,3 b$ \\
\hline \multicolumn{2}{|c|}{ CV (\%) } & 13,74 & 28,74 \\
\hline
\end{tabular}

As médias seguidas de letras distintas, nas colunas, diferem estatisticamente entre si, a $5 \%$ de probabilidade, pelo teste de Tukey

Este resultado difere do constatado por Piza et al. (2001) os quais obtiveram maior frequência de gemas não desenvolvidas nos tratamentos com baixas concentrações de fitorreguladores. Albuquerque et al. (2000) verificaram $100 \%$ de necrose em ápices caulinares de abacaxizeiro da cultivar Pérola, após 45 dias de cultivo em meio MS. Resposta similar foi constatada para a variável altura dos brotos estabelecidos (Tabela 1) revelando que não existem diferenças significativas entre a altura dos brotos estabelecidos na ausência de reguladores de crescimento e aqueles desenvolvidos em meios de cultivo suplementados com $0,5 \mathrm{mg} \mathrm{L}^{-1}$ de BAP $+0,125 \mathrm{mg} \mathrm{L}^{-1}$ de ANA e com 0,5 mg L $\mathrm{m}^{-1}$ de BAP $+0,5 \mathrm{mg} \mathrm{L}^{-1}$ de ANA, verifica-se, ainda, que não houve diferença significativa na altura dos brotos estabelecidos nos meios de cultivo suplementados com reguladores de crescimento, o que se deve, provavelmente, a respostas distintas da cultivar estudada à adição dessas substâncias ao meio na fase de estabelecimento de explantes.

\section{Experimento 2 - Multiplicação}

Verificaram-se as maiores taxas de multiplicação dos brotos foram verificadas no meio de cultivo MS suplementado com 2,0 mg L $\mathrm{mg}^{-1}$ BAP $+0,5 \mathrm{mg} \mathrm{L}^{-1}$ de ANA, durante três subcultivos sucessivos (Tabela 2 ).

Tabela 2. Valores médios da taxa de multiplicação de brotos de abacaxizeiro cv. Emepa 1, aos 30, 60 e 90 dias de cultivo em meio MS suplementado com diferentes concentrações e combinações dos reguladores de crescimento BAP e ANA

\begin{tabular}{|c|c|c|c|c|c|}
\hline \multirow{2}{*}{\multicolumn{2}{|c|}{$\begin{array}{c}\text { Tratamentos (mg L-1) } \\
\text { BAP + ANA }\end{array}$}} & \multicolumn{4}{|c|}{ Subcultivo (dias) } \\
\hline & & \multirow{2}{*}{$\begin{array}{l}30 \\
1,0 \mathrm{~d}\end{array}$} & \multirow{2}{*}{$\begin{array}{l}60 \\
1,4 \text { e }\end{array}$} & \multirow{2}{*}{$\begin{array}{l}90 \\
1,6 \mathrm{e}\end{array}$} & \multirow{2}{*}{$\begin{array}{c}\text { Média } \\
1,3\end{array}$} \\
\hline- & - & & & & \\
\hline 1,0 & - & $2,3 c$ & $4,5 d$ & $6,0 \mathrm{~d}$ & 4,3 \\
\hline 1,5 & - & $2,5 \mathrm{c}$ & $5,7 \mathrm{C}$ & $8,1 \mathrm{C}$ & 5,4 \\
\hline 2,0 & - & $2,7 \mathrm{C}$ & $5,7 \mathrm{C}$ & $8,2 \mathrm{C}$ & 5,5 \\
\hline 2,52 & - & $2,6 \mathrm{C}$ & $5,8 \mathrm{C}$ & $8,1 \mathrm{c}$ & 5,5 \\
\hline 1,0 & 0,01 & $4,1 \mathrm{~b}$ & $8,3 \mathrm{~b}$ & $12,0 \mathrm{~b}$ & 8,1 \\
\hline 2,0 & 0,5 & $5,3 a$ & $10,6 \mathrm{a}$ & $15,4 \mathrm{a}$ & 10,4 \\
\hline 2,0 & 1,0 & $3,9 \mathrm{~b}$ & $8,3 \mathrm{~b}$ & $12,4 \mathrm{~b}$ & 8,2 \\
\hline \multicolumn{2}{|c|}{ CV (\%) } & 19,31 & 12,04 & 8,36 & \\
\hline
\end{tabular}

As médias seguidas de letras distintas, na coluna, diferem entre si a $5 \%$ de probabilidade pelo teste de Tukey

Verifica-se tendência de crescimento na taxa de multiplicação quando se aumenta a concentração de BAP. Este fenômeno pode ser atribuído aos valores do balanço hormonal

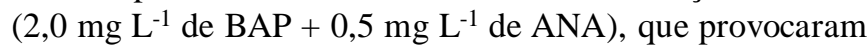
o aumento da taxa de multiplicação e o alongamento dos brotos, respectivamente. Resultados semelhantes foram obtidos por Ramirez \& Bocardo (2003), Almeida et al. (2002), Barboza et al. (2004), Silva et al. (2002), Mogollón et al. (2004) e Piza et al. (2001), para as cultivares Champaka e MD2, Pérola, PE x SC-52, Primavera, Queen Austrália e Smooth Cayenne, respectivamente, revelando comportamentos similares em diversas cultivares aos reguladores de crescimento BAP e ANA, na fase de multiplicação. Os menores valores de multiplicação nos três subcultivos, foram registrados no meio MS sem a adição de reguladores de crescimento.

\section{Experimento 3 - Enraizamento}

Aos 30 dias de cultivo observou-se formação de raízes em todos os tratamentos testados, além de uma relação positiva entre o número de raízes e o aumento da concentração de ANA; entretanto, o comprimento das raízes foi afetado com o aumento da concentração deste regulador de crescimento nos meios de cultivo; isto se deve, sem dúvida, à ação do regulador de crescimento (ANA), que provocou o aumento no número e, consequentemente, a diminuição do tamanho das raízes (Tabela 3 ).

Esses resultados (Tabela 3) se apresentam inferiores porém de comportamento semelhante aos estudados por Ramírez \& Bocardo (2003), que obtiveram, em média, 9,7 e 9,9 raízes nas cultivares MD 2 e Champaka, respectivamente, em meio de cultivo adicionado de $0,2 \mathrm{mg} \mathrm{L}^{-1}$ de ANA; com relação ao comprimento das raízes conseguiram, em média, $2,9 \mathrm{~cm}$ em meio de cultivo sem reguladores de crescimento para as duas cultivares estudadas. De acordo com Piza et al. 
Tabela 3. Número e comprimento médios de raízes em brotos de abacaxizeiro da cultivar Emepa 1 cultivados durante 30 dias em meio de cultura contendo diferentes concentrações de ácido naftalenoacético (ANA)

\begin{tabular}{ccc}
\hline $\begin{array}{c}\text { Tratamentos - ANA } \\
\left(\mathbf{m g ~ L}^{-1}\right)\end{array}$ & Número de raízes & $\begin{array}{c}\text { Comprimento das raízes } \\
(\mathbf{c m})\end{array}$ \\
- & $7,0 \mathrm{c}$ & $2,3 \mathrm{a}$ \\
0,2 & $7,3 \mathrm{C}$ & $1,9 \mathrm{~b}$ \\
1,0 & $11,4 \mathrm{~b}$ & $1,2 \mathrm{C}$ \\
2,0 & $15,8 \mathrm{a}$ & $0,7 \mathrm{~d}$ \\
CV. (\%) & 8,51 & 7,11 \\
\hline
\end{tabular}

As médias seguidas de letras distintas, na coluna, diferem entre si a $5 \%$ de probabilidade pelo teste de Tukey

(2001), o meio de cultivo suplementado de $2 \mathrm{mg} \mathrm{L}^{-1}$ de ANA, foi o mais eficiente no enraizamento de plântulas da cultivar Smooth Cayenne; no entanto, Barboza et al. (2004) observaram que os brotos do híbrido PE x SC-52 e da cultivar Smooth Cayenne multiplicados na presença de BAP a $2 \mathrm{mg} \mathrm{L}^{-1}$ apresentaram melhor desempenho na rizogênese in vitro, independentemente da presença ou ausência de reguladores de crescimento no meio de cultivo.

\section{CONCLUSÕES}

1. O estabelecimento de gemas axilares de abacaxizeiro da cv. EMEPA 1 pode ser realizado em meio de cultivo MS sem a adição de reguladores de crescimento.

2. O meio de cultivo MS, suplementado com BAP e ANA é o mais indicado para multiplicação dos brotos de abacaxizeiro cv. EMEPA 1.

3. A adição de ANA ao meio de cultura promove o aumento do número e a redução do comprimento das raízes mudas micropropagadas de abacaxizeiro, cv.EMEPA 1.

\section{LITERATURA CITADA}

Aghion, D.; Beauchesne, G. Utilization de la technique de culture sterile d'órganes pour des clones d' Ananas. Fruits, v.15, n.10, p.464-466, 1960.

Albuquerque, C. C. Estudos de cultivares de abacaxizeiro (Ananas comosus L. Merr.) propagadas in vitro quanto à resistência a fusariose. Recife: UFRPE, 1998. 85p. Dissertação Mestrado

Albuquerque, C. C.; Câmara, T. R.; Menezes, M.; Willadino, L.; Meunier, I.; Ulisses, C. Cultivo in vitro de ápices caulinares de abacaxizeiro para limpeza clonal em relação à fusariose. Scientia Agrícola, v.57, n.2, p.363-366, 2000.

Almeida, W. A. B. de; Santana, G. S.; Rodriguez, A. P. M.; Costa, M. A. P. de C. Optimization of a protocol for the micropropagation of pineapple. Revista Brasileira de Fruticultura, v.24, n.2, p.296-300, 2002.

Barboza, S. B .S. C.; Caldas, L. S.; Souza, L. A. C. Micropropagação do hibrido PE x SC-52 e da cultivar Smooth cayenne de abacaxizeiro. Pesquisa Agropecuária Brasileira, v.39, n.8, p.725-733, 2004.
Barboza, S. B. S. C.; Graciano-Ribeiro, D.; Teixeira, J. B.; Portes, T. A.; Souza, L. A. C. Anatomia foliar de plantas micropropagadas de abacaxi. Pesquisa Agropecuária Brasileira, v.41, n.2, p.185-194, 2006.

Barroso, P. A. V.; Moura, G. E. D. D.; Brito, L. K. F.; Martins, C. P.; Macedo, C. E. C.; Lopes, D. B.; Alloufa, M. A. I. Efeito do cultivo in vitro na presença de $\mathrm{NaCl}$ em plantas de abacaxizeiro na fase de aclimatação. Revista Brasileira de Engenharia Agrícola e Ambiental, v.7, n.3, p.473-477, 2003.

Cabral, J. R. S.; Cunha, G. A. P.; Rodrigues, E. M. Micropropagação do abacaxizeiro. In.: Congresso Brasileiro de Fruticultura, 5, 1983, Florianópolis. Anais... Florianópolis: SBF, v.1, 1983, p.124-127.

Cunha, G. A. P. da; Reinhardt, D. H. R. C. Manejo de mudas de abacaxi. Cruz das Almas, BA: Embrapa CNPMF, 2004. 4p. Comunicado Técnico, 105

dal Vesco, L. L.; Guerra, M. P.; Pinto, A. de A.; Nodari, R. O. Otimização do protocolo regenerativo in vitro para o abacaxizeiro (Ananas comosus L. Merril). In: Congresso Brasileiro de Fruticultura, 14, 1996, Londrina. Anais... Londrina: IAPAR, 1996. p.561

dal Vesco, L. L.; Pescador, R.; Beló, A.; Feuser, S.; Oliveira, E. N.; Brancher, A.; Zaffari, G. R.; Nodari, R. O.; Guerra, M. P. Qualidade genotípica de mudas e performance a campo de plantas micropropagadas de abacaxizeiro. Revista Brasileira de Fruticultura, v. 22, n.1, p.80-85, 2000.

dal Vesco, L. L.; Pinto, A. de A.; Zaffari, G. R.; Nodari, R. O.; Reis, M. S. dos; Guerra, M.P. Improving pineapple micropropagation protocol through explant size and medium composition manipulation. $2001<\mathrm{http}$ ///www.fruits-journal.org/index. php?option $=$ article $\&$ access $=$ standard $\&$ Itemid $=129 \&$ url $=/$ articles/fruits/pdf/2001/03/dealvesco.pdf. 05 Abr. 2007.

Feuser, S.; Nodari, R. O.; Guerra, M. P. Eficiência comparativa dos sistemas de cultura estacionária e imersão temporária para a micropropagação do abacaxizeiro. Revista Brasileira de Fruticultura, v.23, n.1, p.6-10, 2001.

Firoozabady, E.; Gutterson, N. Cost-effective in vitro propagation methods for pineapple. Plant Cell Reports, v.21, n.9, p.844-850, 2003.

Guerra, M. P.; dal Vesco, L. L.; Pescador, R.; Schuelter, A. R.; Nodari, R. O. Estabelecimento de um protocolo regenerativo para a micropropagação do abacaxizeiro. Pesquisa Agropecuária Brasileira, v.34, n.9, p.1557-1563, 1999.

Liu, L. J.; Rosa-Marquez, E.; Lizardi, E. In vitro propagation of spineless Red Spanish pineapple. Phytopathology, v.12, n.77, p.17-21, 1988.

Macêdo, C. E. C. de; Silva, M. G. da; Nóbrega, F. S. da; Martins, C. P.; Barroso, P. A. V.; Alloufa, M. A. I. Concentrações de ANA e BAP na micropropagação de abacaxizeiro L. Merrill (Ananas comosus) e no cultivo hidropônico das plântulas obtidas in vitro. Revista Brasileira de Fruticultura, v.25, n.3, p.501-504, 2003.

Marciani-Bendezú, J.; Pinto, J. E. B. P.; Pasqual, M. Efeito de 6Benzilaminopurina (BAP) sobre a proliferação de brotos de abacaxizeiro, a partir de plântulas produzidas in vitro. Revista Brasileira de Fruticultura, v.12, n.1, p.35-39, 1990.

Mathews, V. H.; Rongan, T. S. Multiple plantlets in lateral bud and leaf explants in vitro culture of pineapple. Science Horticulturae, v.11, n.4, p.319-328, 1979. 
Mogollón, N.; Díaz, J. G.; Hernandez, N. Multiplicación clonal y enraizamiento in vitro de Ananas comosus L. Queen Australia. 2004. <http://www.revfacagronluz. org.ve/PDF/suplemento_2004/Mogollon\%20et\%20al.pdf>. 30 Jun. 2006.

Moreira, M. A.; Carvalho, J. G. de; Pascoal, M.; Fráguas, C. B.; Silva, A. B. da. Efeito de substratos na aclimatação de mudas micropropagadas de abacaxizeiro cv. Pérola. Ciência Agrotécnica, v.30, n.5, p.875-879, 2006.

Moreira, M. A.; Pasqual, M.; Carvalho, J. G. de; Fráguas, C. B. Estiolamento na micropropagação do abacaxizeiro cv. Pérola. Ciência Agrotécnica, v.27, n.5, p.1002-1006, 2003.

Murashige, T.; Skoog, F. A. A revised medium for rapid growth and bioassays with tabaco tissue cultures. Physiologia Plantarum, v.15, n.3, p.473-497, 1962.

Omokolo, N. D.; Tita, M. A.; Niemenak, N. Régénération directe in vitro de l'Ananas comosus (L.) Merril var. Cayenne à partir de couronnes cultivées em milieu liquide. 2001.http:// www.fruits-journal.org. 15 Jan. 2006.

Piza, I. M. de T.; Lima, G. P. P.; Brasil, O. G. Reguladores vegetais na micropropagação do abacaxizeiro. Revista Ceres, v.48, n.280, p.681-690, 2001.

Praxedes, S. C.; Silva Jr. A. F. da; Figueiredo, F. L. B.; Figueiredo, M. de L.; Câmara, F. A. A.; Oliveira, O. F. de. Estiolamento in vitro do abacaxizeiro pérola em presença de ANA e AIA. Caatinga, v.14, n.1/2, p.13-15, 2001.
Ramírez, B. R.; Bocardo, L. E. Micropropagación y formación de callo de dos cultivares de piña champaka y md2.2003 <http://www.uaaan.mx/DirInv/Rdos2003/cont2003.pdf>. 12 Jan. 2006.

Roca, W. M.; Mroginski, L. A. Cultivo de tejidos en la agricultura: Fundamentos y aplicaciones. 1.ed. Colômbia: Centro Internacional de Agricultura Tropical, 1991. 66p.

Sá, M. E. L. Propagação in vitro de diferentes genótipos de abacaxizeiro por meio de seccionamento de plântulas. Revista Brasileira de Fruticultura, v.23, n.1, p.17-20, 2001.

Silva, A. B. da; Pascoal, M.; Maciel, A. L. de R.; Moreira, M. A.; Dutra, L. F. Influência da benzilaminopurina e do benomyl na proliferação in vitro de abacaxizeiro. Ciência Agrotecnica, v.26, n.6, p.1190-1196, 2002.

Teixeira, J. B.; Cruz, A. R. R.; Ferreira, F. R.; Cabral, J. R. Biotecnologia aplicada à produção de mudas: Produção de mudas micropropagadas de abacaxi. Biotecnologia, Ciência e Desenvolvimento, v.3, n.19, p.42-47, 2001.

Teng, W. L. An alternative propagation method of Ananas through nodule culture. Plant Cell Reports, v.16, p.454-457, 1997.

Ventura, J. A. Fusariose do abacaxizeiro: caracterização do patógeno, epidemiologia da doença, resistência e micropropagação do hospedeiro in vitro. Viçosa: UFV, 1994. 111p. Tese Doutorado 